\title{
Endovascular repair of aneurysm after previous surgical coarctation repair
}

\author{
Michael Gawenda, MD, ${ }^{a}$ Marko Aleksic, MD, ${ }^{a}$ Jörg Heckenkamp, MD, ${ }^{a}$ Karsten Krüger, MD, ${ }^{\text {b }}$ and \\ Jan Brunkwall, MD, $\mathrm{PhD}^{\mathrm{a}}$
}

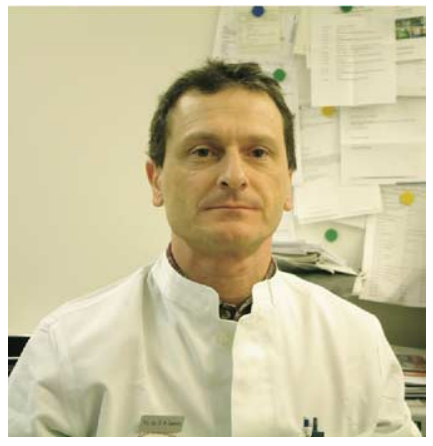

Dr Gawenda
From the Division of Vascular Surgery ${ }^{\mathrm{a}}$ and the Department of Radiology, ${ }^{\mathrm{b}}$ University of Cologne, Cologne, Germany.

Received for publication March 31, 2005; revisions received May 23, 2005; accepted for publication May 26, 2005.

Address for reprints: Michael Gawenda, MD, Associate Professor, Division of Vascular Surgery, Medical Centre, University of Cologne, Germany, Kerpener Str. 62, 50924 Cologne, Germany (E-mail: Michael. gawenda@uk-koeln.de).

J Thorac Cardiovasc Surg 2005;130:1039-43 $0022-5223 / \$ 30.00$

Copyright () 2005 by The American Association for Thoracic Surgery

doi:10.1016/j.jtcvs.2005.05.042
Objectives: Late aneurysm formation has been reported after every type of surgical coarctation repair, with rupture of such aneurysms being responsible for approximately $7 \%$ of all deaths. Secondary surgical repair carries a significant mortality and morbidity. According to the positive experience with endovascular therapy of atherosclerotic thoracic aortic aneurysms, it is worthwhile to evaluate the concept of minimally invasive endovascular stent grafting for secondary repair of postsurgical aneurysms.

Methods: Data were collected prospectively on consecutive patients who presented with postcoarctation false aneurysms.

Results: Since 1999, in a cohort of 46 endovascularly treated patients with thoracic aortic pathologies, 3 patients with postcoarctation false aneurysms underwent endoluminal stent-graft placement. All of these procedures were technically successful without 30-day or 1-year procedure-related mortality. After a mean follow-up of 19 months (range, 7.8-33.5 months), all aneurysm remain excluded without endoleak.

Conclusions: According to the current limited experience of small series and short periods of follow-up, the endoluminal repair seems to be a promising alternative to redo operations for postsurgical thoracic aneurysms associated with coarctation repair. Long-term follow-up is required to assess the durability of the stent-graft treatment.

$\mathrm{S}$ urgically repaired coarctation of the aorta is often regarded as a stable condition throughout the consecutive lifespan. After the operation, the patient might be essentially cured. However, in contrast to this attitude, long-term studies of patients with repaired coarctation of the aorta demonstrated late problems principally caused by recoarctation, hypertension, and premature coronary and cerebrovascular disease, resulting in premature morbidity and even mortality. ${ }^{1}$ Despite the primary operative success, approximately $10 \%$ of patients experience a localized formation of postsurgical aneurysms in the late-term follow-up, ${ }^{2}$ with a rupture-related mortality of $7 \% .^{3}$

The concept of the endovascular stent-graft repair, which has been shown to be feasible, with acceptable intermediate results ${ }^{4-6}$ with regard to the treatment of atherosclerotic aneurysm, could be used also for anastomotic aneurysms to avoid repeat surgical intervention. The aim of this article is to evaluate this method in 3 cases of postcoarctation aneurysm.

\section{Patients and Methods}

Since November 1999, a variety of thoracic aortic pathologies in 46 patients has been treated endovascularly. The mean age of the cohort (31 male and 15 female patients) was 64 years (range, 23-83 years). The patients presented with the following aortic morphology: aneurysm, 16 patients; dissections with aneurysm, 6 patients; dissection without aneurysm, 8 patients; intramural hematoma, 2 patients; penetrating ulcers, 3 patients; 
TABLE 1. Patient characteristics

\begin{tabular}{|c|c|c|c|c|}
\hline Age $(y) / s e x$ & Previous operation for coarctation & $\begin{array}{l}\text { Presenting } \\
\text { symptoms }\end{array}$ & $\begin{array}{c}\text { Size of } \\
\text { aneurysm }(\mathrm{mm})\end{array}$ & Stent graft \\
\hline $50 / \mathrm{M}$ & $\begin{array}{l}\text { Resection with end-to-end anastomosis } \\
(15 \mathrm{y}) \text {, recoarctation followed by } \\
\text { graft interposition ( } 42 \mathrm{y})\end{array}$ & Dyspnea & 65 & $\begin{array}{l}\text { Talent } 42 \times 100 \text {, Talent } \\
\quad 42 \times 100\end{array}$ \\
\hline $35 / \mathrm{M}$ & Graft interposition ( 5 y) & Asymptomatic & 55 & $\begin{array}{l}(\text { Talent } 28 \times 100) \text { Gore } \\
\quad \text { TAG } 31 \times 150\end{array}$ \\
\hline 38/M & Patch angioplasty (13 y) & Back pain & 55 & Gore TAG $34 \times 150$ \\
\hline
\end{tabular}

transection, 6 patients; and false aneurysm, 5 patients. The underlying pathology was as follows: atherosclerotic medial degeneration, 20 patients; acute dissection ( $<14$ days), 7 patients; chronic dissection ( $\geq 14$ days), 8 patients; trauma, 6 patients; and iatrogenic, 5 patients.

Three male patients underwent endovascular repair of postcoarctation false aneurysm (Table 1).
The first patient presented with progressive dyspnea. He had an end-to-end repair of a coarctation at 15 years of age and required a redo operation with a Dacron graft interposition at 42 years of age. At admission, the contrast-enhanced computed tomographic (CT) scan revealed a false aneurysm localized distally to the origin of the left subclavian artery. The bronchoscopy showed compression of the left main bronchus. He
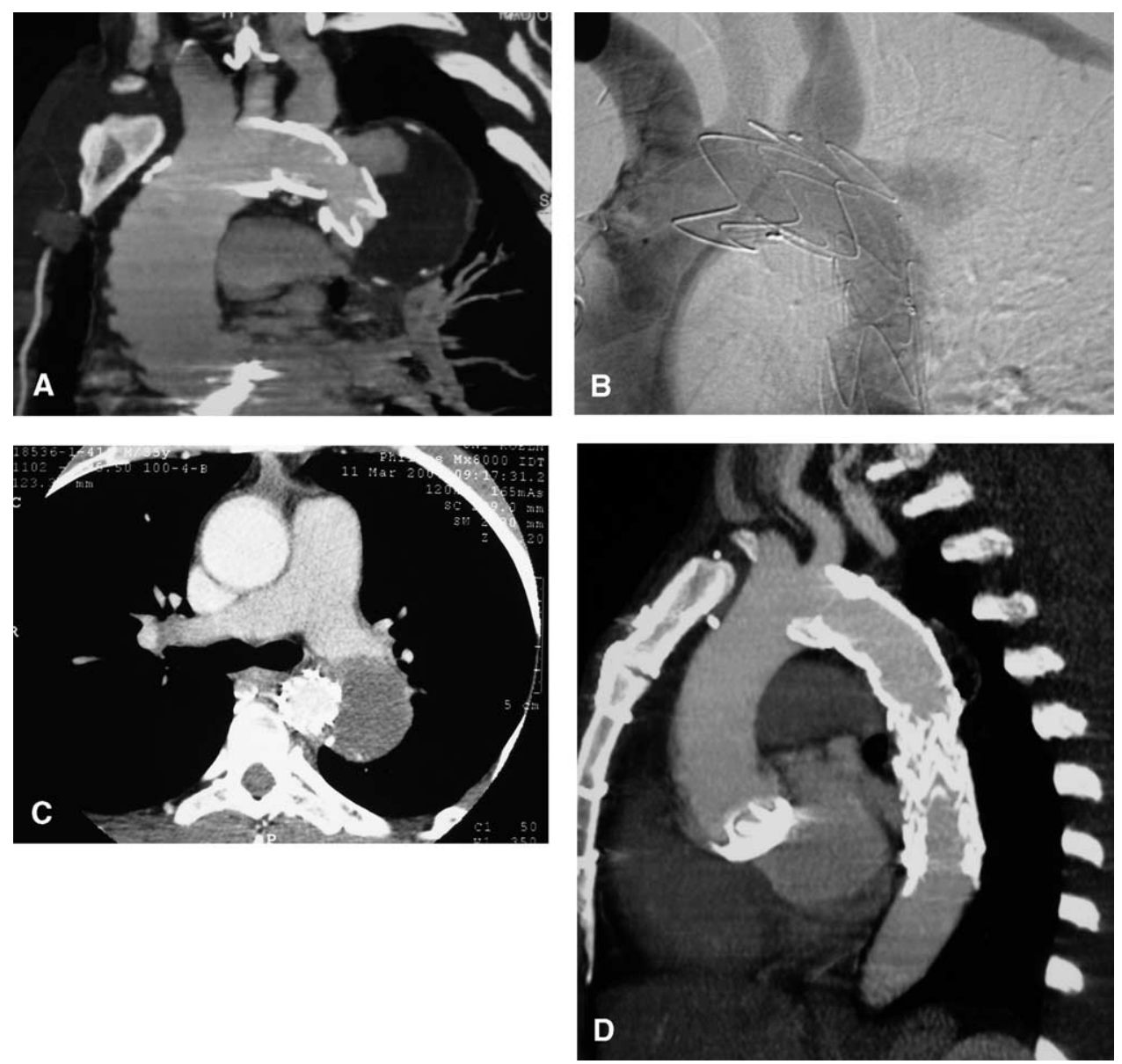

Figure 1. Case 2 (35-year old man). A, Preoperative contrast-enhanced CT of the aortic arch with double-oblique 2-dimensional reconstruction. B, Intraoperative angiography. C, Postoperative CT scan (1 month's follow-up). D, Postoperative contrast-enhanced CT of the aortic arch with double-oblique 2-dimensional reconstruction. The left subclavian artery was covered by the stent. Proximally, the endoprosthesis begins directly behind the ostium of the left common carotid artery (13 months' follow-up). 

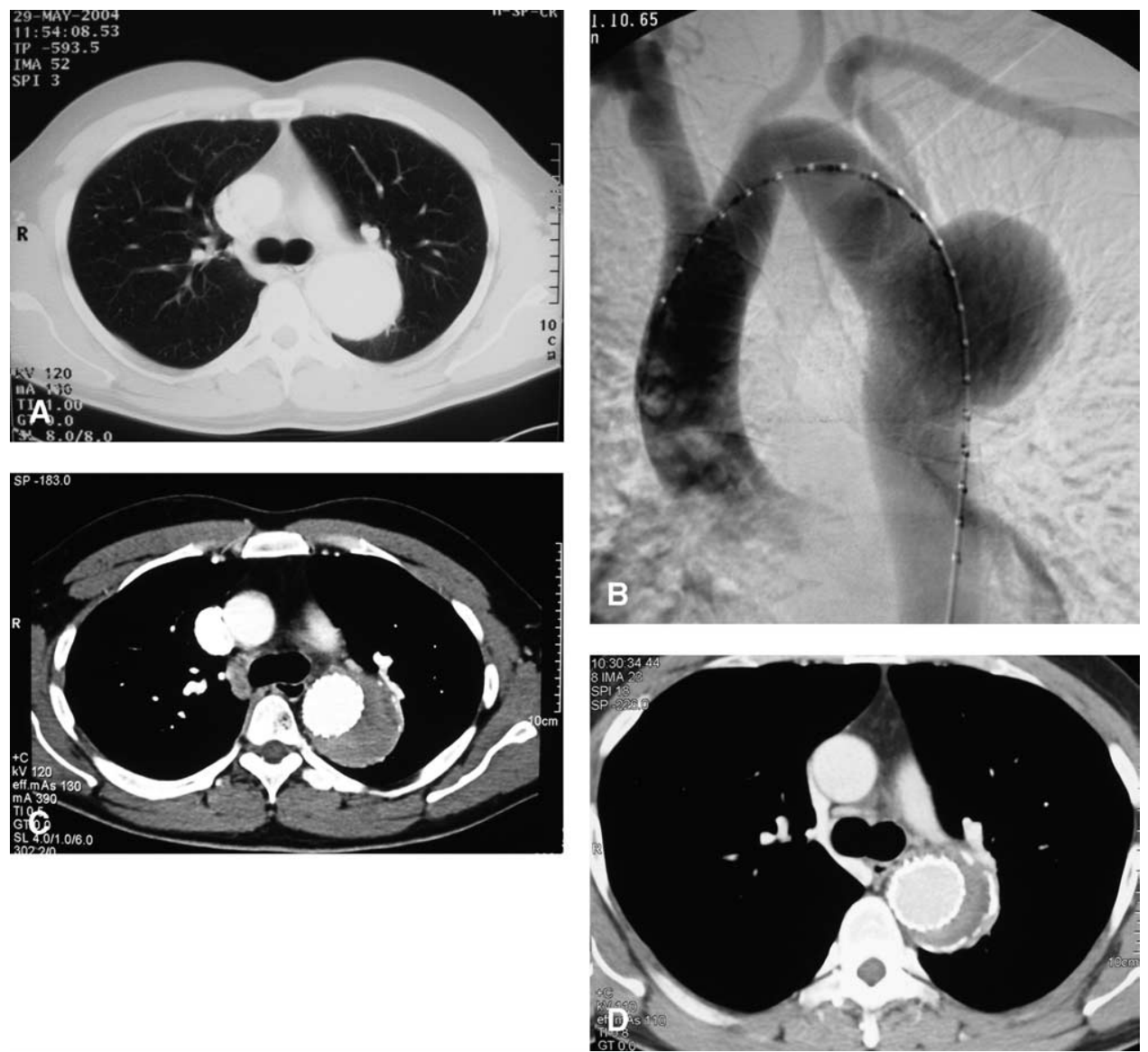

Figure 2. Case 3 (38-year-old man). A, Transverse scan at the level of the aneurysm. B, Preoperative angiography with calibrated cathether. C, Postoperative CT scan (2 months' follow-up). D, Postoperative CT scan (12 months' follow-up).

was treated immediately within 24 hours after admission to our institution.

The second asymptomatic patient was transferred to our center with a diagnosis of a type I endoleak after stent-graft placement (Talent Thoracic Stent Graft System; Medtronic AVE, Sunrise, Fla; $28 \times 28 / 113$ ) at an outside cardiovascular unit. He received a graft interposition 21 years previously for repair of aortic coarctation. The contrast-enhanced CT scan demonstrated the endoleak, which was confirmed by means of intraoperative angiography (Figure 1).

The third patient had a patch angioplasty at 13 years of age and presented with thoracic and interscapular pain. The contrast-enhanced CT scan showed a 55-mm thoracic false aneurysm (Figure 2).

All patients had preoperative thoracic spiral CT angiographies; in the 2 patients undergoing elective procedures, the diagnostics were completed by performing digital subtraction angiographies of the aorta with a calibration catheter. The endovascular devices used in our patients were the Talent Thoracic Stent Graft System (Medtronic AVE) in 1 patient and the GORE TAG Thoracic Endoprosthesis (W. L. Gore and Associates, Flagstaff, Ariz) in 2 patients. The graft diameter was oversized by $10 \%$ to achieve a tight friction seal.
Before the endovascular aneurysm repair, informed consent was obtained from all patients, and a team of vascular surgeons and interventional radiologists performed the endovascular procedures after achievement of peridural anesthesia, as previously described. ${ }^{7}$ Follow-up spiral CT scans were performed at 3, 6, and 12 months and then yearly thereafter.

\section{Results}

Transfemoral stent-graft deployment was uneventful and technically successful in all 3 patients. No patient died. Postdeployment angiography confirmed the exclusion of the false aneurysms without any endoleak in all patients. In 1 patient (case 3) local dissection of the common femoral artery was repaired by means of endarterectomy and patch angioplasty. None of the patients who had intended covering of the left subclavian artery became symptomatic, and therefore no patient required revascularization of the left arm, although the placement over the ostium of the left subclavian artery led to a $50 \%$ reduction in distal arterial pressure. All 3 patients were discharged from the hospital within 1 week. 

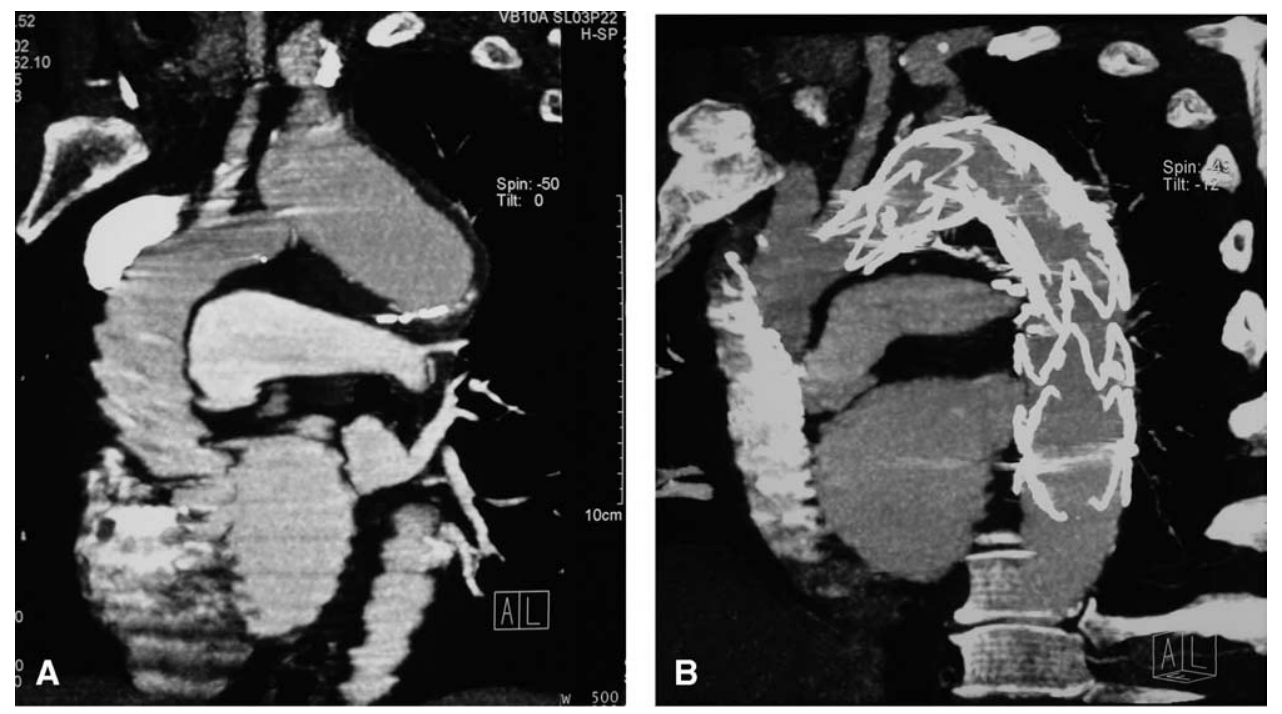

Figure 3. Case 1 (50-year-old man). CT angiograms with double-oblique 2-dimensional reconstruction. A, CT scan preoperatively. B, CT scan after follow-up of 26 months.

The mean follow-up was 19 months $(7.8,16$, and 33.5 months, respectively). Until now, contrast-enhanced CT scans confirmed the endoleak-free exclusion of all endovascularly treated postcoarctation aneurysms without stentgraft migration of the stent graft (Figure 3).

\section{Discussion}

Late aneurysm formation has been reported after every type of surgical coarctation repair. The incidence of aneurysm formation is increasing with time. Although a postsurgical aneurysm was observed in $17 \%$ after subclavian flap angioplasty, reports of late aneurysm formation after Dacron patch aortoplasty range from $5 \%$ to $38 \%$ of cases. ${ }^{8}$ Similarly, tube graft repair or end-to-end anastomosis is followed by rates of $6 \%$ respectively $3 \%$ of postcoarctation false aneurysms. ${ }^{2}$ The rupture of such aneurysms is thought to be responsible for approximately $7 \%$ of all deaths. ${ }^{3}$

Conservative treatment of aneurysms after surgical coarctation repair remains unpredictable and was associated with a $100 \%$ rate of rupture within 15 years in a single-center experience. ${ }^{9}$ On the other hand, secondary surgical repair carries significant mortality and morbidity, including paralysis of the recurrent nerve, bleeding, and paraplegia. ${ }^{10-12}$

According to the promising experience with the endovascular therapy of atherosclerotic thoracic aortic aneurysms, it is rather attractive to evaluate the concept of minimally invasive endovascular stent grafts for secondary repair of postcoarctation false aneurysms. This approach has been tested only by 2 other groups. Ince and colleagues ${ }^{13}$ reported their experience with a cohort of 6 endoluminally treated patients in 2003. Using the Talent Thoracic Stent
Graft System, they achieved technical success in 4 false postcoarctation aneurysms after previously performed patch aortoplasty. In 2 other cases the patch angioplasty had been followed by type I aortic dissection, which was succeeded by aortic root reconstruction and elephant trunk. During the median follow-up of 17.5 months (range, 11-47 months), one patient died of a procedure-unrelated cause. Magnetic resonance imaging documented normal patency of stent grafts and retraction of the aneurysm. ${ }^{13}$

Bell and coworkers ${ }^{14}$ treated 3 patients after previous patch aortoplasty and 1 patient after left subclavian aortoplasty with the GORE TAG Thoracic Endoprosthesis. The procedures were technically successful in all cases without any mortality. During median follow-up of 7 months (range, 3-29 months), all aneurysms remained excluded without evidence of endoleak or stent migration. ${ }^{14}$

Our own experience of endoluminal false aneurysm exclusion after coarctation surgery extends the currently existing series with small case loads and short follow-up.

Thus endoluminal repair seems to be a promising and less-invasive alternative compared with redo operations for postsurgical thoracic aneurysms associated with coarctation repair and otherwise caused prosthetic graft interpositions. Long-term follow-up with cross-sectional imaging is required to assess the durability of the stent graft as a therapeutic concept in this entity of aortic diseases.

\section{References}

1. Celermajer DS, Greaves K. Survivors of coarctation repair: fixed but not cured. Heart. 2002;88:113-4. 
2. von Kodolitsch Y, Aydin MA, Koschyk DH, Loose R, Schalwat I, Karck M, et al. Predictors of aneurysmal formation after surgical correction of aortic coarctation. J Am Coll Cardiol. 2002;39:61724.

3. Cohen M, Fuster V, Steele PM, Driscoll D, McGoon DC. Coarctation of the aorta. Long-term follow-up and prediction of outcome after surgical correction. Circulation. 1989;80:840-5.

4. Brunkwall J, Gawenda M, Sudkamp M, Zahringer M. Current indication for endovascular treatment of thoracic aneurysms. J Cardiovasc Surg (Torino). 2003;44:465-70.

5. Bergeron P, De Chaumaray T, Gay J, Douillez V. Endovascular treatment of thoracic aortic aneurysms. J Cardiovasc Surg (Torino). 2003;44:349-61.

6. Demers P, Miller DC, Mitchell RS, Kee ST, Sze D, Razavi MK, et al. Midterm results of endovascular repair of descending thoracic aortic aneurysms with first-generation stent grafts. $J$ Thorac Cardiovasc Surg. 2004;127:664-73.

7. Gawenda M, Landwehr P, Brunkwall J. Stent-graft replacement of chronic traumatic aneurysm of the thoracic aorta after blunt chest trauma. J Cardiovasc Surg (Torino). 2002;43:705-9.
8. Kron IL, Flanagan TL, Rheuban KS, Carpenter MA, Gutgesell HP Jr, Blackbourne $\mathrm{LH}$, et al. Incidence and risk of reintervention after coarctation repair. Ann Thorac Surg. 1990;49:920-6.

9. Knyshov GV, Sitar LL, Glagola MD, Atamanyuk MY. Aortic aneurysms at the site of the repair of coarctation of the aorta: a review of 48 patients. Ann Thorac Surg. 1996;61:935-9.

10. Ala-Kulju K, Heikkinen L. Aneurysms after patch graft aortoplasty for coarctation of the aorta: long-term results of surgical management. Ann Thorac Surg. 1989;47:853-6.

11. Kieffer E, Bahnini A, Koskas F. Aberrant subclavian artery: surgical treatment in thirty-three adult patients. J Vasc Surg. 1994;19:100-10.

12. Rokkas CK, Murphy SF, Kouchoukos NT. Aortic coarctation in the adult: management of complications and coexisting arterial abnormalities with hypothermic cardiopulmonary bypass and circulatory arrest. J Thorac Cardiovasc Surg. 2002;124:155-61.

13. Ince H, Petzsch M, Rehders T, Kische S, Korber T, Weber F, et al. Percutaneous endovascular repair of aneurysm after previous coarctation surgery. Circulation. 2003;108:2967-70.

14. Bell RE, Taylor PR, Aukett M, Young CP, Anderson DR, Reidy JF. Endoluminal repair of aneurysms associated with coarctation. Ann Thorac Surg. 2003;75:530-3. 